\title{
Analysis on Seismic Performance of Steel Rreinforced High Strength Concrete Columns
}

\author{
Xin $\mathrm{YI}^{1, \mathrm{a}}$, Heping $\mathrm{Hu}^{2, \mathrm{~b}}$,Changqing Guo $\mathrm{O}^{2, \mathrm{c}}$ and BingJie $\mathrm{MI}^{1, \mathrm{~d}}$ \\ ${ }^{1}$ School of Urban Construction, University of South China, China \\ ${ }^{2}$ School of Mathematics and Physics, University of South China, China \\ ayixinmbj@126.com, bhuheping99@126.com, cguocq@hotmail.com ,d2323075462@qq.com
}

Keywords: Steel high strength concrete column, seismic performance, axial compression ratio, stirrup ratio, steel ratio, finite element analysis.

\begin{abstract}
In the thesis, simulated analysis of eight steel reinforced high strength concrete column under the low reversed cyclic horizontal load were performed by using the nonlinear finite element software of ABAQUS. The hysteresis behavior, skeleton curve, displacement ductility energy-dissipating capacity of the steel reinforced concrete column under the combined action of the bending, pressing, and shearing were discussed in this thesis. And it also analyzed factors that affect the bearing capacity and ductility of the steel reinforced column, such as axial compression ratio, stirrup ratio, steel ratio. Results indicate that the displacement ductility factor between 2.43 and 3.95; The stirrup ratio have a greater impact on the seismic performance of steel reinforced high strength concrete columns. With the increment of volume-stirrup ratio and steel ratio, the ductility factor increases; As The axial compression ratio increased, bearing capacity increased correspondingly; When steel reinforced concrete column are under higher axial pressure, stirrup ratio has more significant effect on the bearing capacity of structure.
\end{abstract}

\section{Introduction}

In recent years, the investigation of damage caused by earthquakes shows whether building collapse depends on the performance of columns in great part. And the steel reinforced high strength conerete structure is a new type of structure[1], which is developed rapidly in recent years. This structure has many advantages: higher bearing capacity, stronger stiffness, the better seismic behavoirs and the durability. Therefore, research on the seismic performance of steel reinforced column is of great significance.

Experiment takes not only much time but also energy, even so, research can't be done comprehensively. With the rapid development of computer technology and the nonlinear finite element theory being gradually improved, research on finite element simulation analysis is particularly important in modern scientific researches and engineering systems. In the thesis, it designed eight steel reinforced concrete frame columns, and discussed several factors that affect the hysteretic curve, skeleton curve, ductility and energy-dissipation capacity of steel reinforced high strength concrete column, such as, axial compression ratio, stirrup ratio, steel ratio. All of these provide a reference to for houses designing.

The model parameters. The finite element model is reference to literature [2]. Designed a total of eight SRC columns model. SRC-1 adopt ordinary rectangular hoop. SR-C-2 to SRC-6 adopt octagonal compound hoop. SRC-7 to SRC-8 adopt rectangular plus-angle hoop. Steel reinforced concrete columns of dimensions and reinforcement section were shown in Figure 1, the model parameters wa-s shown in Table.1. 


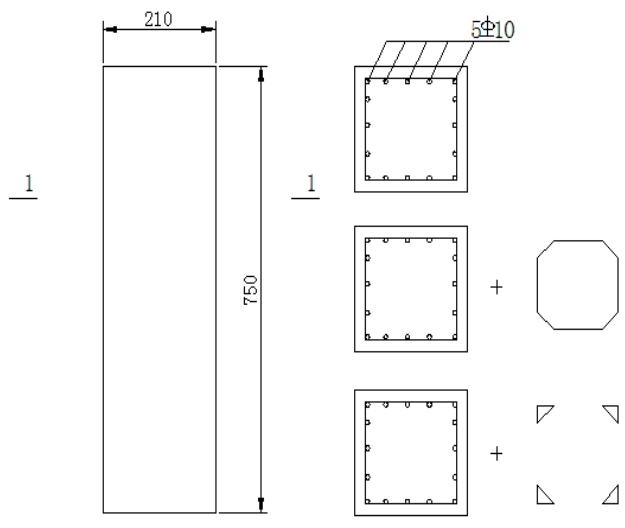

Fig. 1 Specimen dimension and reinforced detail

Tab. 1 Design parameters for models

\begin{tabular}{ccccccc}
\hline No. & $\begin{array}{c}\text { Sectional } \\
\text { dimension } \\
/ \mathrm{mm}\end{array}$ & $\begin{array}{c}\text { Axial } \\
\text { load } \\
\text { ratio }\end{array}$ & $\begin{array}{c}\text { Steel } \\
\text { Specificati- } \\
\text { ons }\end{array}$ & $\begin{array}{c}\text { Ratio of } \\
\text { steel } \\
/ \rho_{\mathrm{s}}\end{array}$ & $\begin{array}{c}\text { Stirrup } \\
\text { configuration }\end{array}$ & $\begin{array}{c}\text { Stirrup } \\
\text { ratio }\end{array}$ \\
\hline SRC-1 & $210 \times 210$ & 0.4 & $\mathrm{I} 14$ & $9.5 \%$ & $\square 6 @ 100$ & $0.66 \%$ \\
SRC-2 & $210 \times 210$ & 0.4 & $\mathrm{I} 14$ & $9.5 \%$ & $\square 6 @ 100$ & $0.98 \%$ \\
SRC-3 & $210 \times 210$ & 0.2 & $\mathrm{I} 14$ & $9.5 \%$ & $\square 6 @ 100$ & $0.98 \%$ \\
SRC-4 & $210 \times 210$ & 0.6 & $\mathrm{I} 14$ & $9.5 \%$ & $\square 6 @ 100$ & $0.98 \%$ \\
SRC-5 & $210 \times 210$ & 0.4 & $\mathrm{I} 10$ & $6.4 \%$ & $\square 60100$ & $0.98 \%$ \\
SRC-6 & $210 \times 210$ & 0.4 & $\mathrm{I} 12$ & $7.9 \%$ & $\square 60100$ & $0.98 \%$ \\
SRC-7 & $210 \times 210$ & 0.4 & $\mathrm{I} 14$ & $9.5 \%$ & $\square 6 @ 75$ & $1.30 \%$ \\
SRC-8 & $210 \times 210$ & 0.4 & $\mathrm{I} 14$ & $9.5 \%$ & $\square 8 @ 110$ & $1.58 \%$ \\
\hline
\end{tabular}

\section{Finite element simulations}

The constitutive relation. Concrete damaged plasticity model build-in ABAQUS was adopted, which suitable for simulating the concrete structure behavior of low cyclic loading. The model data were referred to the code of concrete [3].

Table. 2 Input parameters of the concrete material

\begin{tabular}{|c|c|c|c|c|c|c|}
\hline$\rho\left(\mathrm{t} / \mathrm{mm}^{3}\right)$ & $\begin{array}{c}\text { Young's modulus } \\
\text { /GPa }\end{array}$ & $\begin{array}{l}\text { Poisson's } \\
\text { ratio }\end{array}$ & $E_{c c}$ & $\begin{array}{l}f_{\mathrm{b} 0} \\
/ f_{\mathrm{c} 0}\end{array}$ & $\begin{array}{c}\text { Dilation } \\
\text { angle }\end{array}$ & $\begin{array}{l}\text { Viscosity } \\
\text { parameter }\end{array}$ \\
\hline $2.4 \times 10^{-9}$ & 38 & 0.2 & 0.667 & 1.16 & 30 & 0.01 \\
\hline \multicolumn{7}{|c|}{ Table 3 Input parameters of the reinforced material } \\
\hline Steel & Type & $\begin{array}{l}\text { Young's modulu } \\
\mathrm{s} / 10^{5} \mathrm{MPa}\end{array}$ & $\begin{array}{l}\text { Poison' } \\
\text { s ratio }\end{array}$ & $\begin{array}{c}\text { Yield } \\
\text { strengt } \\
\text { h /MPa }\end{array}$ & \multicolumn{2}{|c|}{$\begin{array}{l}\text { Ultimate strength } \\
\quad \text { a }\end{array}$} \\
\hline \multirow{2}{*}{ Shaped steel } & Wing & 2.07 & 0.3 & 319.7 & \multirow{2}{*}{\multicolumn{2}{|c|}{$\begin{array}{l}491.5 \\
502.5\end{array}$}} \\
\hline & Web & 2.07 & 0.3 & 312.4 & & \\
\hline $\begin{array}{l}\text { Longitudinal } \\
\text { reinforcement }\end{array}$ & 10 & 2.06 & 0.3 & 386.3 & \multicolumn{2}{|c|}{495.7} \\
\hline \multirow{2}{*}{ Stirrups } & 6 & 2.07 & 0.3 & 397.5 & \multirow{2}{*}{\multicolumn{2}{|c|}{$\begin{array}{l}438.0 \\
457.3 \\
\end{array}$}} \\
\hline & 8 & 2.07 & 0.3 & 354.5 & & \\
\hline
\end{tabular}

Double linear model was used in the constitutive relation of steel bar[4]. The increased slope of the model curve is elastic modulus of steel bar before yield and the straight line represents the yielding stress of the steel bar. The ultimate tensile strain of steel bar is 0.2 .

Material characteristics. The strength of concrete was C80, and longitudinal reinforcement and stirrup were the level II steel. The parameters of concrete material were shown in Table 2, and the parameters of reinforced material were shown in Table 3. 
Establishment of finite element model. In the thesis, the modeling of bridge pier was used eight node hexahedron linear reduced integral unit C3D8R to simulate concrete and three dimension two node linear truss element T3D2 to simulate steel bar. The "Embedded Region" was applied to describe the bond between reinforcement and concrete. In order to prevent the damages of the top of the pier due to stress concentration during vertical load applied the top of pier, the distribution and coupling constraints was adopted between the loading point and the top of the pier in the "Interaction" module, which made the top surface into rigid and conformed to the experiment that steel was put to the top of the column. The distribution and coupling constraints was also used between the lateral displacement of loading point and surface loading, and the bottom of the pier was set to fixed supports. The size of the grid is used $30 \mathrm{~mm} \times 30 \mathrm{~mm}$. The finite element model was shown in Figure 2.

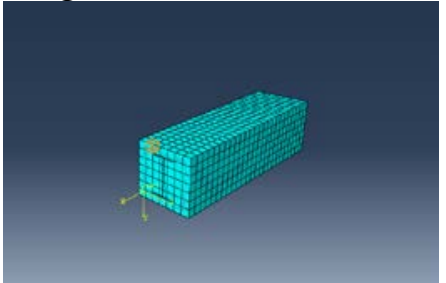

(a) Concrete model

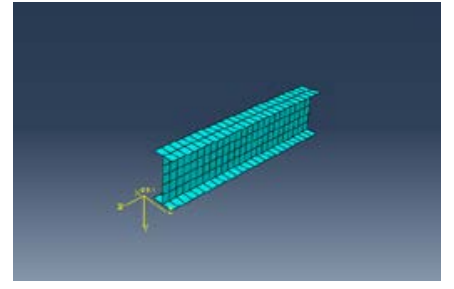

(b) Section steel model

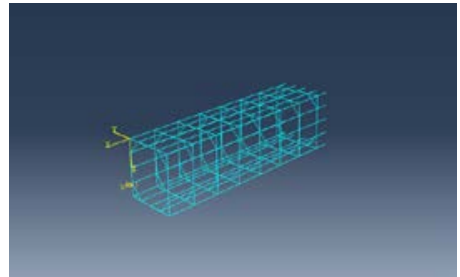

(c) Reinforced model

Fig. 2 Finite element model

\section{Analysis of computing result}

Hysteretic curve. The hysteresis curve of component is an important performance of seismic structure, the more the hysteresis fullness, the stronger the artifacts dissipation seismic capacity, and then the seismic performance of structure is better. The force-displacement response of component at point of lateral loads will be show in Fig.3.

During the early loading, the model is in the stage of flexible work. The force-displacement response curve of component is linear relationship, the residual displacement is very small and deformation mainly recovery. so the area of the hysteresis curve surrounded is very small. After the model to yield, Load slow growth. There are many residual deformation after unloading curve and the area of the hysteresis curve have further increased. It show that the energy dissipation capacity increased gradually. When the hysteresis curve reaches limit load, the bearing capacity drops rapidly due to the slip between steel bar and reinforced concrete.

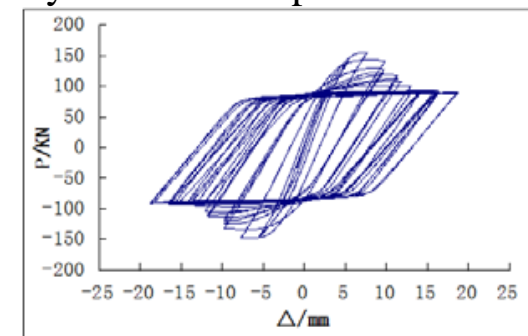

(a) SRC-1

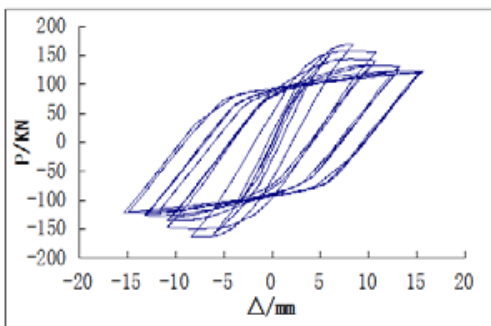

(d) SRC-4

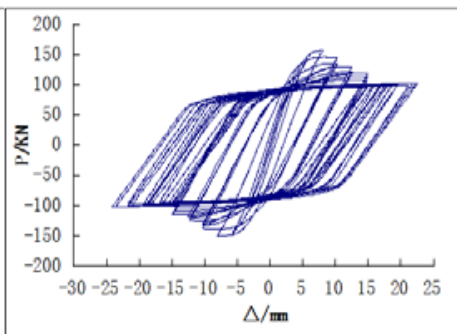

(b) SRC-2

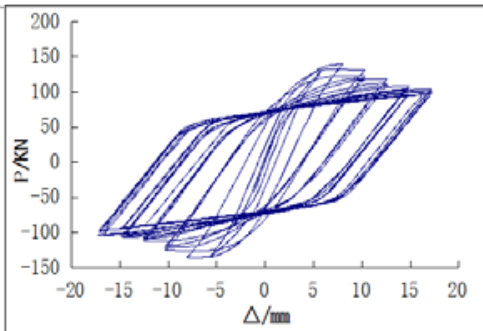

(e) SRC-5

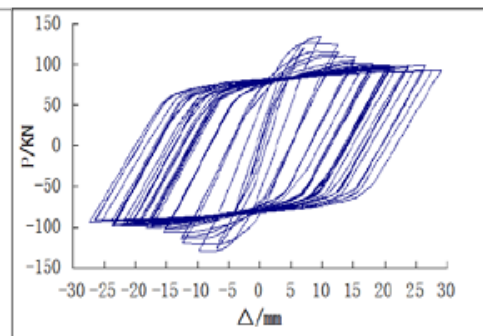

(c) SRC-3

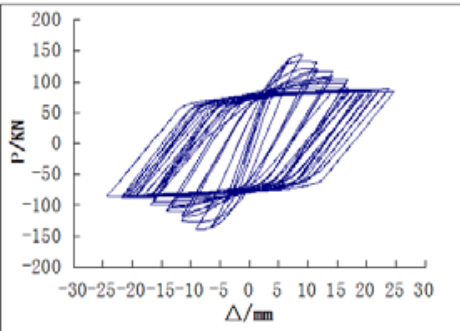

(f) SRC-6 


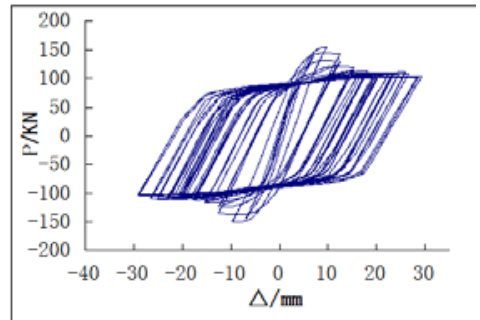

(g) SRC-7

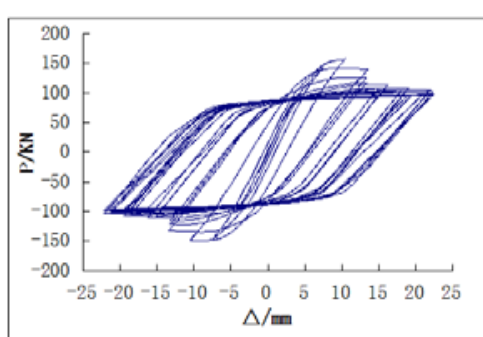

(h) SRC-8

Fig. 3 Hysteric curves of specimens

Skeleton curve. The curve of the peaks of the first cycle at all levels are connected envelope called skeleton curves. The skeleton curve of the component is shown in Fig.4.

The influence of axial compression ratio. By figure 4 (a) to be seen, with the increase of axial compression ratio, the stiffness of specimen initial larger; After the peak value, the falling section of skeleton curve is relatively steeper, it showed that the strength decrease rapidly and the ductility is poor.

The influence of stirrup ratio. By Figure 4 (b) to be seen, with the increase of steel ratio, the deformation capacity increased significantly; after the peak load, the falling section of skeleton curve is relatively flat, it suggesting that the slow decay of strength and the ductility is good.

The influence of steel ratio. Figure 4 (c), SRC-2, SRC-7, stirrup ratio from $0.98 \%$ to $1.3 \%$, ductility coefficient from 4.22 to 4.58 , increasing by $8.5 \%$.

The influence of stirrup forms. In the axial compression ratio and stirrup ratio under the same conditions, the ductility factor of configuring octagonal composite hoop component, SRC-2 than ordinary rectangular hoop SRC-1 increase in 24.5\%, the SRC-7 and SRC-1, compared to an increase of the angle of the hoop, the ductility factor was increased by $35.1 \%$, and the deformation capacity has improved significantly.

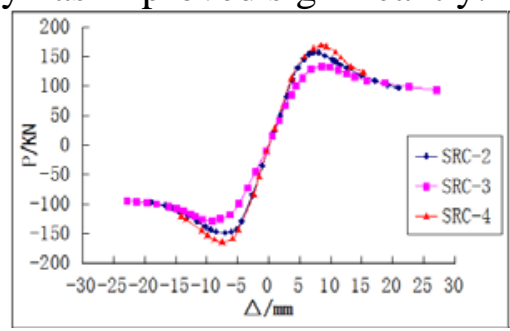

(a) Different axial Compression ratio

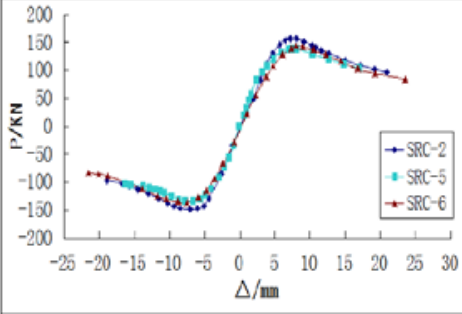

(b) Different ratio of steel

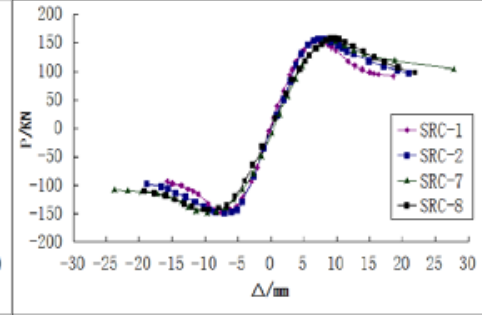

(c) Different stirrup ratio

Fig. 4 Comparison of skeleton curves

Displacement ductility coefficient. The yield displacement $\Delta y$ was obtained by the moment method[5, 6]. When the bearing capacity decreased to $0.85 \mathrm{Fmax}$, the corresponding displacement was taken as the ultimate displacement $\Delta \mathrm{u}$. And then the displacement ductility coefficient was expressed as $\mu=\Delta \mathrm{u} / \Delta \mathrm{y}$. The displacement ductility coefficient $\mu$ of the models were shown in table 4.

The existing research have shown that [7], the reinforced concrete frame column displacement ductility coefficient is about 2.0, while the steel reinforced concrete frame column displacement ductility coefficient is about 4.0. In this thesis, the average displacement ductility factor of each specimen was 3.82, its higher than the reinforced concrete frame columns. However, it has high strength concrete brittleness, which the average displacement ductility coefficient is lower than the ordinary steel concrete column. Looking at the results from finite element analysis, each Specimen has good ductility. 
Tab. 4 Displacement ductility of specimens

\begin{tabular}{cccccccc}
\hline No. & $\mathrm{P}_{\mathrm{y}} / \mathrm{kN}$ & $\triangle_{\mathrm{y}} / \mathrm{mm}$ & $\mathrm{P}_{\mathrm{m}} / \mathrm{kN}$ & $\triangle_{\mathrm{m}} / \mathrm{mm}$ & $\mathrm{P}_{\mathrm{u}} / \mathrm{kN}$ & $\triangle_{\mathrm{u}} / \mathrm{mm}$ & $\mu=\triangle_{\mathrm{u}} /$ \\
\hline SRC-1 & 123.9 & 3.2 & 155.3 & 7.6 & 132.0 & 9.7 & 3.03 \\
SRC-2 & 126.4 & 3.3 & 156.55 & 8.1 & 133.1 & 10.3 & 3.27 \\
SRC-3 & 104.5 & 3.5 & 134.1 & 9.7 & 114.2 & 12.58 & 3.59 \\
SRC-4 & 140.8 & 4.2 & 169.3 & $8, .4$ & 143.9 & 10.54 & 2.52 \\
SRC-5 & 120.5 & 4.4 & 139.4 & 7.8 & 118.5 & 10.68 & 2.43 \\
SRC-6 & 110.6 & 4.2 & 144.3 & 9.1 & 122.7 & 11.57 & 2.75 \\
SRC-7 & 115.9 & 3.1 & 155.2 & 9.7 & 131.9 & 12.26 & 3.95 \\
SRC-8 & 124.7 & 4.1 & 156.5 & 10.13 & 132.9 & 12.95 & 3.15 \\
\hline
\end{tabular}

\section{Summary}

Adopt to ABAQUS finite element simulation, the parameters correctly set, accurately build of each model, choose suitable analysis steps, reasonable to meshing and set appropriately boundary conditions, we can get a better simulation results, the calculation results with higher accuracy degrees.

The displacement ductility factor between 2.43 and 3.95; The stirrup ratio have a greater impact on the seismic performance of steel reinforced high strength concrete columns.

As the axial compression ratio increased,its bearing capacity increased correspondingly, but the energy dissipation capacity of the specimen deterioration and the ductility decreased.

Hysteresis loop of high strength steel reinforced concrete columns is relatively full, the initial stiffness of skeleton curve is relatively large; after the peak load, it has a more gentle descent stage, which have a good ductility and energy dissipation capacity.

\section{References}

[1] Hongtie Zhao, Steel reinforced concrete composite structure[M]. Beijing: Science Press,2001. ( in Chinese)

[2] BinWang, Shansuo Zheng, Xianfa Guo, Lei Li, Experimental research on mechanical behavior of SRHSHPC frame columns under cyclic loading.[J]. Journal of Building Structures.2011(03). ( in Chinese)

[3] GB50010-2010, Code for design of concrete structures [S]. Beijing: Chinese Building Industry Press, 2010. (In Chinese)

[4] Zhenhai Guo, Xuhai Shi, Reinforced Concrete Theory and Analyse [M]. Beijing: Tsinghua University Press, 2003:134-135. (In Chinese)

[5] Park,R, Evaluation of Ductilitry of Structures and Structural Assemblages from Laboratory Testing[J].Bulletin of the New Zealand National Society for Earthquake Engineering.Vol.22.NO3. September.1989.

[6] Bolong Zhu et al, Seismic test of structures [M]. Beijing: Seismological Press, 1989. (In Chinese)

[7] Lianguang Wang, Theory and calculation of steel and concrete composite structures[ M] . Beijing: Science Press, 2005. (in Chinese) 